\title{
Primary Extraskeletal Osteosarcoma of Sigmoid Mesocolon: A Case Report and a Review of the Literature
}

\section{Xinyang Nie}

Tianjin Medical University General Hospital

\section{Weihua Fu}

Tianjin Medical University General Hospital

\section{Chuan Li}

Tianjin Medical University General Hospital

\section{Lu Li}

Tianjin Medical University General Hospital

Weidong Li ( $\square$ tjmughgs_lwd@163.com )

Tianjin Medical University General Hospital

\section{Research Article}

Keywords: Mesentery, Sigmoid mesocolon, Extraskeletal, Extraosseous, Osteosarcoma.

Posted Date: March 30th, 2021

DOI: https://doi.org/10.21203/rs.3.rs-349322/v1

License: () (1) This work is licensed under a Creative Commons Attribution 4.0 International License. Read Full License 


\section{Abstract}

Background: Extraskeletal osteosarcoma (ESOS) is a very rare mesenchymal malignancy, characterized by the production of osteoid, bone or chondroid material and typically located in the soft tissue without attachment to skeletal bones and periosteum. One of the things that ESOS originated from mesentery is much rarer.

Case presentation: A 75-year female with a more than 4-months history of pain in the left lower abdomen. Abdominal computerized tomography and magnetic resonance imaging revealed a large, irregular and solid-cystic mass, which largest diameter was $11.5 \mathrm{~cm}$. The tumor was radically removed during open operation. The tumor was composed of abundant osteoid and polyhedral-shaped tumor cells with high atypia and high mitotic activity microscopically. The final pathological diagnosis was osteoblastic osteosarcoma, arising from the sigmoid mesocolon with negative margins. The patient was followed up 5 months after surgery and found no signs of systemic metastasis

Conclusion: Given the rarity of cases of mesenteric ESOS, diagnosis mainly depended on pathology findings or should be taken into consideration when the mesenteric mass was found. Its most effective treatment had not been determined, with surgical excision was generally accepted. Negative surgical margin may be an important factor affecting the prognosis.

\section{Background}

Extraskeletal osteosarcoma (ESOS) is a very rare mesenchymal malignancy that usually occurs in the fifth or sixth decades of life, first described in 1941 by Wilson.[1] Generally, the tumor is characterized by the production of osteoid, bone or chondroid material and usually located in the soft tissue without attachment to skeletal bones and periosteum,[2] most commonly in deep soft tissues of the lower extremities, but also in the upper extremities and retroperitoneum.[3] Low incidence of ESOS has been reported, accounting for only $4 \%$ of osteosarcoma and approximately $1 \%$ of soft tissue sarcoma.[4-6] ESOS arising from mesentery are extremely rare. Radical surgical resection is still the main treatment for ESOS.[7] Here we described a case of primary ESOS arising from sigmoid mesocolon.

\section{Case Report}

A 75-year-old woman with no history of malignancy was referred to our hospital in August,2020 with a more than 4-months history of pain in the left lower abdomen. No history of trauma, previous radiation or a family history of genetic diseases. There was no history of dark or bloody stools, but she reported a recent change in bowel habits nearly 2 months which was transient constipation that led to frequent use of laxatives. She had $3 \mathrm{~kg}$ weight loss over the previous months.

Physical examination revealed a protuberant abdomen with a large, hard, nonpulsatile but painless mass in the left lower abdomen. Cardiovascular and respiratory examinations were unremarkable. Laboratory findings including serum electrolytes, and hepatic and renal functions were within normal limits, as was the 
serum alkaline phosphatase: $60 \mathrm{U} / \mathrm{L}(40-150 \mathrm{U} / \mathrm{L})$. Standard blood examination showed a decreasing blood count $\left(3.09 * 10^{\wedge} 12 / \mathrm{L}\left(3.80-5.10^{*} 10^{\wedge} 12 / \mathrm{L}\right)\right)$ and hemoglobin concentration $(92 \mathrm{~g} / \mathrm{L}(115-150 \mathrm{~g} / \mathrm{L}))$. Tumor markers such as AFP, CA199, HCG, HE4 and CEA were all normal, but CA125 was markedly elevated:585.60 U/mL (0-35.0 U/mL). Following an abdominal ultrasonography, a solid-cystic and spaceoccupying mass and blood flow signal can be seen inside. An abdominal computerized tomography (CT) scan revealed the mass was adjacent to the left uterine adnexa area and closely related to the sigmoid colon, along with multiple lymph nodes were seen in the pelvic and abdominal cavity. Magnetic resonance imaging revealed a large, irregular, multilocular, solid-cystic, and complex signal mass shadow. The solid part was isointense on both T1 and T2 images. Part of the mass was obviously hyperintense on DWI (Fig. 1).

During an exploratory laparotomy, a large solid-cystic mass was identified in the mesocolon of the sigmoid with invasion into the sigmoid and the small intestine. It fixed on the posterior abdominal wall, accompanied by multiple ruptures and active hemorrhage on the surface. Multiple small hard nodules were found in the small bowel mesentery and sigmoid mesocolon. The tumor was resected en bloc with the sigmoid, ileocecal junction, part of the small bowel, bilateral fallopian tubes and ovaries. The resected tumor measured showed $11.5 \mathrm{~cm} * 7 \mathrm{~cm} * 6.5 \mathrm{~cm}$. The others small lesions in the mesentery were also completely resected. Microscopically, the tumor had a heterogeneous aspect. The others small masses were demonstrated as focal ossification nodules. The tumor was composed of polyhedral-shaped tumor cells and abundant osteoid. The tumor cells had high atypia, high mitotic activity, and atypical mitotic morphology. The eosinophilic osteoid matrix could be found intimately admixed with the tumor cells, presenting focal deposition. By immunohistochemistry, the neoplastic cells were positive for Vimentin, SATB2, BCl2, SDHB and CD99, but negative for cytokeratin, epithelial membrane antigen, desmin, CD117, CD34, Dog-1 and S-100. Part of them were positive for smooth muscle-actin and CD68, and Ki-67 positive rate was about $60 \%$ (Fig. 2). The final pathological diagnosis was osteoblastic osteosarcoma, arising from the sigmoid mesocolon with negative margins and no lymph nodes or blood vessels invasion. After the diagnosis was established, a whole-body bone scan revealed no evidence of osseous metastatic disease. Therefore, the sigmoid mesocolon was considered as the primary lesion. Telephone follow-up 6 months after the operation showed that the general condition of the patient was good.

\section{Discussion}

Extraskeletal osteosarcoma (ESOS), also known as soft tissue osteosarcoma, is a rare malignant neoplasm that produces osteoid, bone or chondroid material with no involvement of bone or periosteum. Although the first report described in 1941[1], few cases have been reported in the literature so far. [2] ESOS are most frequently found in the lower extremity, particularly in the deep soft tissue of the thigh ( $42 \%-77 \%)$, followed by the upper extremity $(12 \%)$. It has also been reported that have been found in the retroperitoneum (12\%). Other relatively rare sites such as the larynx, kidney, esophagus, small intestine, liver, heart, urinary bladder, parotid and breast have been reported before. $[2,4]$ In contrast to skeletal osteosarcoma, which always occurs in patients in the first 3 decades of life, the majority of ESOS occurs in the fifth and seventh decades of life and at a mean reported age of 60 years. [6, 8] Males are slightly more 
than females, with a ratio of 1.9:1.[7, 9] Controversially, there were also statistics showed the male predominance seen in primary osteosarcoma was not found among patients with ESOS. [2]Through the etiology of the ESOS is difficult to pin down precisely, some reports revealed it could be related to radiation, such as previous exposure to $\mathrm{X}$-rays and radioactive thorium dioxide,or at least 4 years after receiving highdose radiation therapy.[10] In addition, some reports revealed $12-30 \%$ of patients have been experienced trauma, and some cases could occur after ossifying myositis.[11, 12] However in our case, the patient had no history of trauma and radiation. Symptoms mainly included a painful or painless mass that grew slowly and progressively of ESOS in the abdominal cavity. The mass was large generally when the patient sought treatment. If the mass invades the bowel, changes in defecation characteristics may occur, including constipation and blood-tinged stool. It is visible on ultrasonic, CT, and MRI as a large soft-tissue mass with a lack of osseous involvement.[3, 7, 11, 13,14] The ESOS is not specific on imaging, the radiological features described in some cases is a calcified mass on CT, but is a solid-cystic mass in our case.[3, 7] On MRI, the lesion shows slightly hyperintense to muscle also nonspecifically on T1-weighted imaging and high signal intensity on T2-weighted imaging, which is not same with the results in our case.[15] The diagnosis of ESOS should be determined in combination with clinical manifestations, radiographical and pathological findings and only after excluding the possibility of primary bone tumor or bone tumor metastatic to soft tissue.[4] For atypical clinical and radiographic manifestations such as the patient in our case, pathology may be the final diagnostic criterion particularly for ESOS in the abdominal cavity. Pathological subtypes of ESOS can be divided into six types. One of the most common is the osteoblastic variant such as in our case with abundant osteoid, outside of that, followed by chondroblasts, fibroblasts/pleiomorphic malignant fibrous histiocytoma like, telangiectasis, small cell and mixed types.[4, 8] Surgery is the main treatment for ESOS. Depending on differences in location, range and development of the tumor, a simple resection, wide resection or radical resection could be selected. Besides, preoperative radiotherapy and adjuvant chemotherapy are also available as treatment options for ESOS. According to statistical reports that expanding the scope of surgery can reduce the local recurrence rate, but it has no special significance for prolonging the survival time.[9] According to the current situation, the regimens and effects of chemotherapy remain controversial for ESOS. Ahmad et al.[16] reported that 27 patients were treated with the doxorubicin-based chemotherapy with an effective rate of $19 \%$ in 60 ESOS patients. Wang et al.[8] reported that the majority of cases received chemotherapy regimens based on methotrexate, adriamycin, and cisplatin. A minority received adriamycin-based and ifosfamide-based therapy. However, survival benefits have not been demonstrated between different chemotherapy regimens or between the people who received chemotherapy and those who did not. Besides when patients are unable to accept the surgical treatment or tolerate high dose chemotherapy or advanced disease, radiotherapy could be chosen as palliative treatment. There have been reported that preoperative or postoperative radiotherapy was thought to be beneficial in reducing the volume of tumors and local recurrence, but no specific improvement in overall survival or progression-free survival, also no difference in death due to disease or event-free survival..[2, 8] For patients who cannot achieve negative surgical margin, radiotherapy is significant to improve overall survival.[8] Regardless of the origin and location of the tumor, the prognosis is poor of ESOS. EOSO has a high risk of local recurrence as well as distant metastasis. Combined with the results of multiple reports, the local recurrence rate was approximately $18 \%-19 \%$ and distant metastasis was $37 \%-38 \% .[2,16]$ According to the reports, approximately $39 \%$ patients died of the disease at 3 years,[2] 
and approximately $75 \%$ die within 5 years of diagnosis.[13] Tumor size is an important factor affecting the prognosis, as the patients with the tumor larger than $5 \mathrm{~cm}$ have worse clinical outcomes. Bane et al.[4] reported that the mortality rate associated with the disease for patients was about $14.3 \%$ ( 1 of 7 patients) with the tumor smaller than $5 \mathrm{~cm}$, but was $87.5 \%$ (14 of 16 patients) with the tumor larger than $5 \mathrm{~cm}$. Besides, positive margin after operating is also an important factor that affects overall survival and local recurrence. Tumors with positive margins have the higher risk of local recurrence and lower survival rate after 5 years. As for patients presenting with non-metastatic disease, the local control rate was about $89 \%$ at 5 years, which was no significant difference between positive and negative margins. At 10 years, local control rate with negative margins was no significant change, but reduced significantly with positive margins.[8] In the presented case, the patient was an elderly women with a large tumor $(>5 \mathrm{~cm}$ in size), negative margin and without adjuvant treatment. No systemic metastases were observed at 2 months postoperatively. It was also difficult for us to predict the prognosis of the patient.

Otherwise, we summarize the reports of ESOS of mesentery so far in English literature (Table 1). It includes the basic characteristics of the patient, the condition of the tumor, treatment and prognosis during initial diagnosis. $[3,7,13,14,17-21]$ The average age of the 10 patients (5 males) was 57 years (range, 39 to 75 years). The tumor was larger than $10 \mathrm{~cm}$ of 7 patients. All of them underwent surgery, only 3 accepted chemotherapy. By comparison, there was no significant improvement in prognosis. It remains a challenge to determine the optimal treatment for ESOS of the mesentery.

\section{Declarations}

\section{Availability of data and materials}

Data sharing is not applicable to this article as no datasets were generated or analysed during the current study.

\section{Acknowledgements}

The authors thank the patient and her family who generously agreed to be interviewed for this research.

\section{Consent for publication}

Written informed consent for publication of their clinical details and clinical images was obtained from the patient.

\section{Conflict of Interest}

The authors declare that the research was conducted in the absence of any commercial or financial relationships that could be construed as a potential conflict of interest. 


\section{Author Contributions}

Xinyang Nie performed the manuscript writing and the literature collecting; Weidong Li and Chuan Li were involved in the operation; Weidong Li, Weihua Fu and Li Lu conceived, designed, and supervised all studies and the drafting and editing of the manuscript. All the authors have read and approved the final manuscript.

\section{Finding}

There is no funding source.

\section{Ethics approval and consent to participate}

Not applicable.

\section{References}

1. Wilson H. EXTRASKELETAL OSSIFYING TUMORS. Ann Surg. 1941;113:95-112. https://doi.org/10.1097/00000658-194101000-00013.

2. Choi LE, Healey JH, Kuk D, Brennan MF. Analysis of outcomes in extraskeletal osteosarcoma: a review of fifty-three cases. J Bone Joint Surg Am. 2014;96:e2. https://doi.org/10.2106/jbjs.M.00339.

3. Choudur HN, Munk PL, Nielson TO, Ryan AG. Primary mesenteric extraskeletal osteosarcoma in the pelvic cavity. Skeletal Radiol. 2005;34:649 - 52. https://doi.org/10.1007/s00256-005-0909-8.

4. Bane BL, Evans HL, Ro JY, Carrasco CH, Grignon DJ, Benjamin RS and Ayala AG. Extraskeletal osteosarcoma. A clinicopathologic review of 26 cases. Cancer. 1990;65:276270.https://doi.org/10.1002/1097-0142(19900615)65:12<2762::aid-cncr2820651226>3.0.co;2-k

5. Hoch M, Ali S, Agrawal S, Wang C, Khurana JS. Extraskeletal osteosarcoma: a case report and review of the literature. J Radiol Case Rep. 2013;7:15-23. .https://doi.org/10.3941/jrcr.v7i7.1245.

6. Thampi S, Matthay KK, Boscardin WJ, Goldsby R, DuBois. SG. Clinical Features and Outcomes Differ between Skeletal and Extraskeletal Osteosarcoma. Sarcoma. 2014;2014:902620. .https://doi.org/10.1155/2014/902620.

7. van den Broek NEJ, Willemsen P, Mattelaer C. A primary extraskeletal osteosarcoma of the mesentery: a case report. Acta Chir Belg. 2018;118:125-8. https://doi.org/10.1080/00015458.2017.1316619.

8. Wang H, Miao R, Jacobson A, Harmon D, Choy E, Hornicek F, Raskin K, Chebib I, DeLaney TF, Chen YE. Extraskeletal osteosarcoma: A large series treated at a single institution. Rare Tumors. 2018. 10:2036361317749651.https://doi.org/10.1177/2036361317749651.

9. Lee JS, Fetsch JF, Wasdhal DA, Lee BP, Pritchard DJ and Nascimento AG. A review of 40 patients with extraskeletal osteosarcoma. Cancer. 1995;76:2253-9.https://doi.org/10.1002/10970142(19951201)76:11<2253::aid-cncr2820761112>3.0.co;2-8 
10. Lee WR, Laurie J and Townsend AL. Fine structure of a radiation-induced osteogenic sarcoma. Cancer. 1975;36:1414-25.https://doi.org/10.1002/1097-0142(197510)36:4<1414::aid-

cncr2820360433>3.0.c0;2-8

11. Chung EB and Enzinger FM. Extraskeletal osteosarcoma. Cancer. 1987;60:1132-

42.https://doi.org/10.1002/1097-0142(19870901)60:5<1132::aid-cncr2820600536>3.0.c0;2-I

12. Wilson JD, Montague CJ, Salcuni P, Bordi C, Rosai J. Heterotopic mesenteric ossification ('intraabdominal myositis ossificans'): report of five cases. Am J Surg Pathol. 1999;23:1464-70. .https://doi.org/10.1097/00000478-199912000-00003.

13. Heukamp LC, Knoblich A, Rausch E, Friedrichs N, Schildhaus HU, Kahl P, Tismer R, Schneider B, Büttner R. and Houshdaran F. Extraosseous osteosarcoma arising from the small intestinal mesentery. Pathol Res Pract. 2007;203:473-7. .https://doi.org/10.1016/j.prp.2007.03.005.

14. Lee KH, Joo JK, Kim DY, Lee JS, Choi C, Lee JH. Mesenteric extraskeletal osteosarcoma with telangiectatic features: a case report. BMC Cancer. 2007;7:82. .https://doi.org/10.1186/1471-2407-782.

15. Varma DG, Ayala AG, Guo SQ, Moulopoulos LA, Kim EE, Charnsangavej C. MRI of extraskeletal osteosarcoma. J Comput Assist Tomogr. 1993;17:414-7. .https://doi.org/10.1097/00004728$199305000-00015$.

16. Ahmad SA, Patel SR, Ballo MT, Baker TP, Yasko AW, Wang X, Feig BW, Hunt KK, Lin PP, Weber KL, Chen LL, Zagars GK, Pollock RE, Benjamin RS, Pisters PW. Extraosseous osteosarcoma: response to treatment and long-term outcome. J Clin Oncol. 2002;20:521-7. .https://doi.org/10.1200/jco.2002.20.2.521.

17. Fine $G$ and Stout AP. Osteogenic sarcoma of the extraskeletal soft tissues. Cancer. 1956;9:102743.https://doi.org/10.1002/1097-0142(195609/10)9:5<1027::aid-cncr2820090522>3.0.co;2-k

18. Hussain MI, Al-Akeely MH, Alam MK, Jasser NA. Extraskeletal osteosarcoma, telangiectatic variant arising from the small bowel mesentery. Saudi Med J. 2011;32:958-61.

19. Ito S, Terado Y, Shimojima R, Hara Y, Narita K, Tachimori Y, Goto M. Primary extraskeletal osteosarcoma of the mesentery: A case report. Int J Surg Case Rep. 2019;60:111-4. https://doi.org/10.1016/j.ijscr.2019.05.058.

20. Shirazi PH, Rayudu GV, Fordham EW. Extraosseous osteogenic sarcoma of the small bowel demonstrated by 18 F scanning. J Nucl Med. 1973;14:295-6.

21. Oh SJ, Chang HK. Unusual giant cell-rich variant of extraskeletal osteosarcoma in the mesentery of small intestine. Int J Clin Exp Pathol. 2017;10:11225-9.

\section{Tables}


Table 1

Literature review of ESOS of the mesentery cases

\begin{tabular}{|c|c|c|c|c|c|c|c|c|}
\hline & $\begin{array}{l}\text { Author } \\
\text { (year) }\end{array}$ & Sex & Age & $\begin{array}{l}\text { Size } \\
\text { (cm) }\end{array}$ & Surgery & Adjuvant therapy & Margin & Prognosis \\
\hline 1 & $\begin{array}{l}\text { Fine G } \\
(1956) \\
{[17]}\end{array}$ & $M$ & 39 & - & $\mathrm{Y}$ & - & - & Dead \\
\hline 2 & $\begin{array}{l}\text { Shirazi P } \\
\mathrm{H} \\
(1973) \\
{[20]}\end{array}$ & $\mathrm{F}$ & 56 & - & Y & $\mathrm{N}$ & - & Dead \\
\hline 3 & $\begin{array}{l}\text { Choudur } \\
\text { HN } \\
(2005)[3]\end{array}$ & M & 45 & 15 & $Y$ & $\begin{array}{l}\text { Doxorubicin } \\
\text { cisplatin }\end{array}$ & - & Alive \\
\hline 4 & $\begin{array}{l}\text { Heukamp } \\
\text { LC } \\
(2007) \\
{[13]}\end{array}$ & $M$ & 61 & 20 & Y & $\begin{array}{l}\text { Doxorubicin } \\
\text { cisplatin } \\
\text { cyclophosphamide } \\
\text { ifosfamide }\end{array}$ & - & Dead \\
\hline 5 & $\begin{array}{l}\text { Lee KH } \\
(2007) \\
{[14]}\end{array}$ & $M$ & 67 & 18 & $Y$ & $\begin{array}{l}\text { Ifosfamide } \\
\text { adriamycin }\end{array}$ & - & Dead \\
\hline 6 & $\begin{array}{l}\text { Hussain } \\
\text { MI } \\
(2011) \\
{[18]}\end{array}$ & $M$ & 40 & 13 & $Y$ & - & - & - \\
\hline 7 & $\begin{array}{l}\text { Oh SJ } \\
(2017) \\
{[21]}\end{array}$ & $\mathrm{F}$ & 70 & 15 & $Y$ & $\mathrm{~N}$ & - & Dead \\
\hline 8 & $\begin{array}{l}\text { Van den } \\
\text { Broek } \\
\text { (2018)[7] }\end{array}$ & $\mathrm{F}$ & 71 & 14 & $Y$ & $\mathrm{~N}$ & - & $\begin{array}{l}\text { Alive } \\
\text { (peritoneal } \\
\text { metastasis) }\end{array}$ \\
\hline 9 & $\begin{array}{l}\text { Ito S } \\
(2018) \\
{[19]}\end{array}$ & $\mathrm{F}$ & 46 & 3.8 & $Y$ & $\mathrm{~N}$ & - & $\begin{array}{l}\text { Alive } \\
\text { (10 months } \\
\text { postoperatively) }\end{array}$ \\
\hline 10 & $\begin{array}{l}\text { Our case } \\
(2021)\end{array}$ & $\mathrm{F}$ & 75 & 11.5 & Y & $\mathrm{N}$ & Negative & $\begin{array}{l}\text { Alive } \\
\text { (6 months } \\
\text { postoperatively) }\end{array}$ \\
\hline
\end{tabular}

Figures 

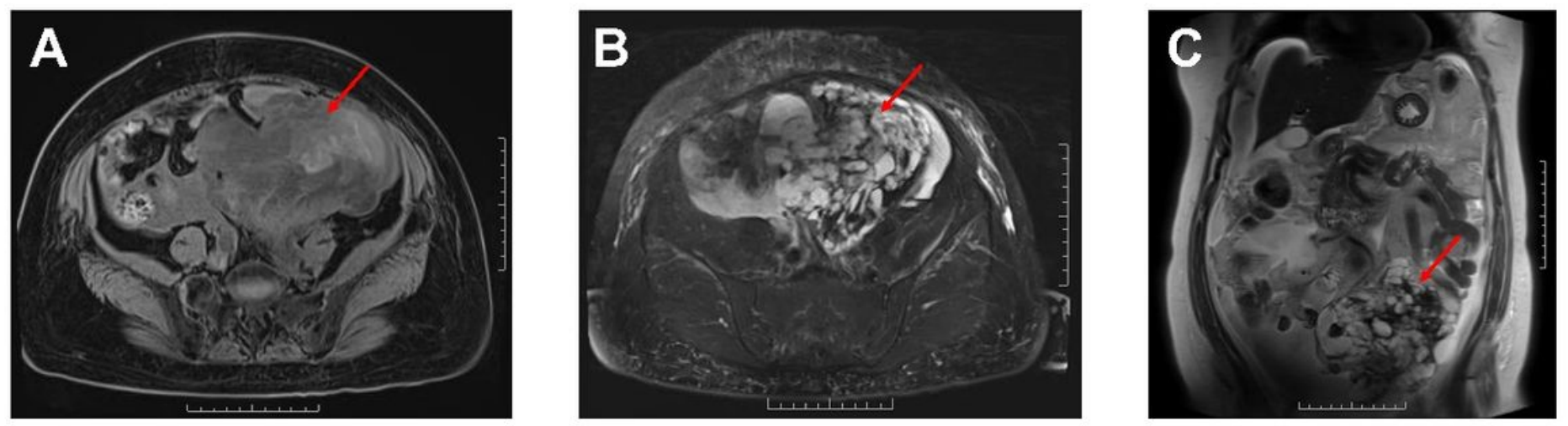

Figure 1

Magnetic resonance imaging: A. T1 imaging (transverse plane); B. T2 imaging (transverse plane); C. T2 imaging (coronal plane).
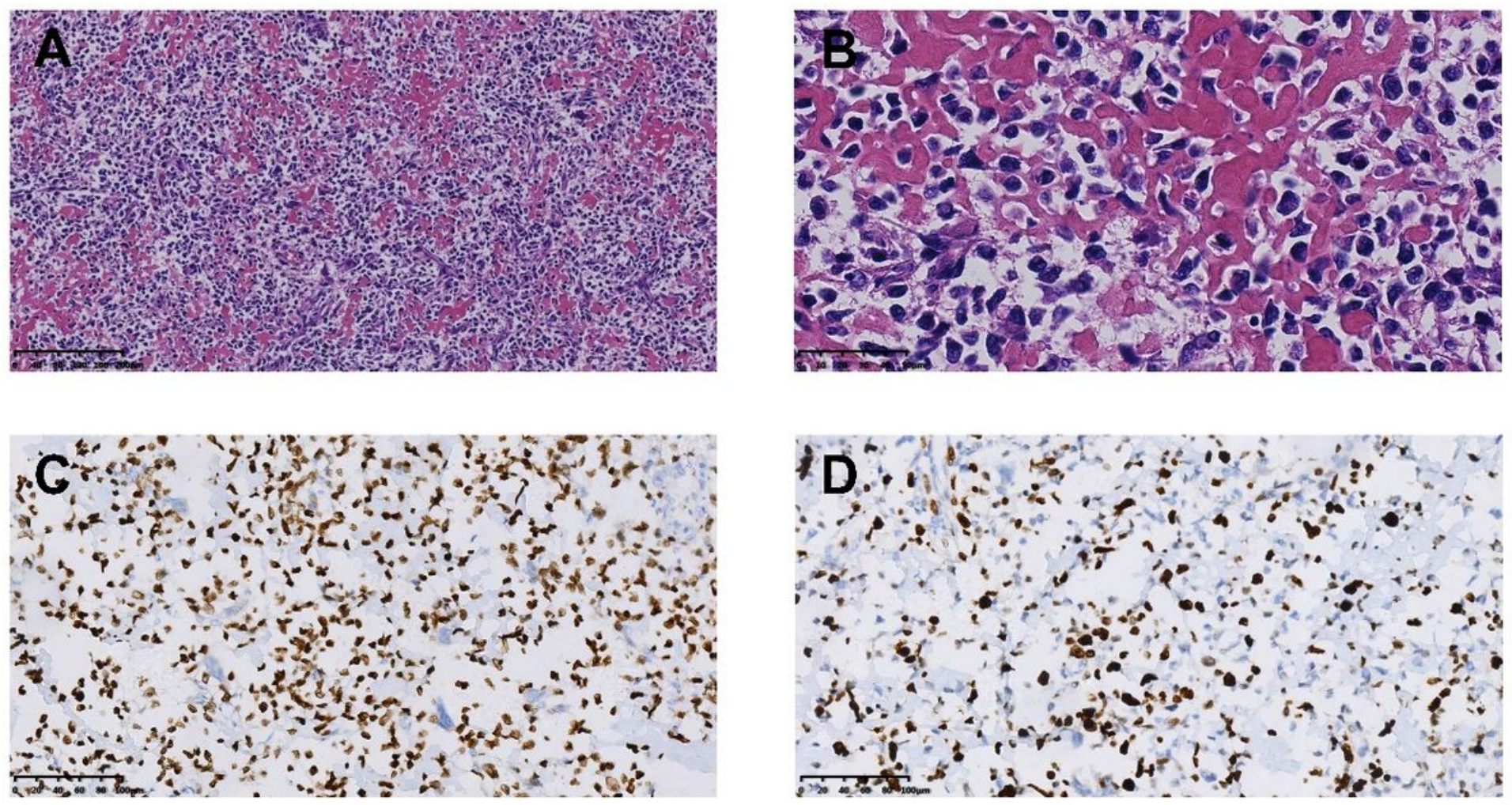

\section{Figure 2}

Histologic sections of the tumor: A. HE-stained section. Original magnification $\times 100$; $B$. HE-stained section. Original magnification $\times 400$; C. Immunohistochemical staining results with SATB2. Original magnification $\times 200$; D. Immunohistochemical staining results with Ki-67. Original magnification $\times 200$. 